\title{
Visualization of Nitric Oxide, Measurement of Nitrosothiols Content, Activity of NOS and NR in Wheat Seedlings \\ Sandeep B. Adavi ${ }^{1}$, Lekshmy Sathee ${ }^{1, *}$, Birendra K. Padhan ${ }^{1}$, Ompal Singh ${ }^{1}$, Hari S. Meena ${ }^{1}$, Kumar Durgesh ${ }^{2}$ and Shailendra K. Jha ${ }^{2}$
}

\begin{abstract}
1Division of Plant Physiology, ICAR-IARI, New Delhi, India; ${ }^{2}$ Division of Genetics, ICAR-IARI, New Delhi, India
\end{abstract}

*For correspondence: lekshmyrnair@gmail.com

[Abstract] Nitric oxide (NO), is a redox-active, endogenous signalling molecule involved in the regulation of numerous processes. It plays a crucial role in adaptation and tolerance to various abiotic and biotic stresses. In higher plants, NO is produced-either by enzymatic or non-enzymatic reduction of nitrite-and an oxidative pathway requiring a putative nitric oxide synthase (NOS)-like enzyme. There are several methods to measure NO production: mass spectrometry, tissue localization by DAF-FM dye. Electron paramagnetic resonance (EPR) also known as electron spin resonance (ESR) and spectrophotometric assays. The activity of NOS can be measured by L-citrulline based assay and spectroscopic method (NADPH utilization method). A major route for the transfer of NO bioactivity is Snitrosylation, the addition of a NO moiety to a protein cysteine thiol forming an S-nitrosothiol (SNO). This experimental method describes visualization of NO using DAF-FM dye by fluorescence microscopy (Zeiss AXIOSKOP 2). The whole procedure is simplified, so it is easy to perform but has a high sensitivity for NO detection. In addition, spectrophotometry based protocols for assay of NOS, Nitrate Reductase (NR) and the content of S-nitrosothiols are also described. These spectrophotometric protocols are easy to perform, less expensive and sufficiently sensitive assays which provide adequate information on NO based regulation of physiological processes depending on the treatments of interest.

Keywords: Nitric oxide (NO), Nitric oxide synthase (NOS)-like enzyme, Nitrate Reductase (NR), Diaminofluorescein-FM (DAF-FM), S-nitrosothiol

[Background] Nitric oxide (NO) is emerging as a key regulator of diverse plant cellular processes like regulating synthesis of the cell wall (Correa-Aragunde et al., 2008; Xiong et al., 2009; Ye et al., 2015), ROS metabolism in plants (Delledonne et al., 2001), gene expression and regulation (Bogdan et al., 2000), programmed cell death (de Pinto et al., 2002), maturation and senescence (Yaacov et al., 1998). NO exerts a crucial role in protecting plants against various abiotic stresses (Hung et al., 2002). NO could significantly enhance antioxidative capacity by increasing the activities of catalase (CAT), ascorbate peroxidase (APX) and accumulating proline during wheat seed germination under osmotic stress (Zhang et al., 2003). A major route for the transfer of NO bioactivity is S-nitrosylation, the addition of a NO moiety to a protein cysteine thiol forming an S-nitrosothiol (SNO). Total cellular levels of protein S-nitrosylation are controlled predominantly by S-nitrosoglutathione reductase 1 (GSNOR1) which turns 
over the natural NO donor, S-nitrosoglutathione (GSNO). In the absence of GSNOR1 function, GSNO accumulates, leading to dysregulation of total cellular S-nitrosylation (Yun et al., 2016)

Nitric oxide (NO) production in land plants classically involves two main routes: first, a reductive pathway involving both enzymatic and non-enzymatic reduction of nitrite into NO (Gupta et al., 2011); second, an oxidative pathway requiring a putative nitric oxide synthase (NOS)-like enzyme. Role of NR in NO production was suspected by low or no NR activity mutants which show no measurable NO. Later nia1/nia2 double mutants of Arabidopsis confirmed the role of $\mathrm{NR}$ in reduction of $\mathrm{NO}_{2}{ }^{-}$to $\mathrm{NO}$ in $\mathrm{NADH}$ dependent manner under both in vitro (Yamasaki et al., 1999) and in vivo (Vanin et al., 2004) condition. The possibility that NOS could catalyze NO synthesis in plants has also been a main controversial issue. Experimental evidence further increased suspicion about the existence of a plant NOS-like enzyme. It was reported that the L-citrulline based assay commonly used to measure a NOS activity in plant extracts is prone to artefacts (Tischner et al., 2007).

Several methods have been reported for nitric oxide assay in plants which includes gas chromatography and mass spectrometry (Neil et al., 2003; Conarth et al., 2004, Bethke et al., 2004), laser photo-acoustic spectroscopy (Lesham and Pinchasov, 2000), NO electrode (Yamasaki et al., 2001), electron paramagnetic resonance (EPR) (Sun et al., 2018) and a group of florescent dye indicators which are available in acetylated form for intracellular measurements like Diaminofluorescein-FM (DAF-FM) (Du et al., 2016). Fluorescent dye indicator and EPR both are highly specific for NO. EPR is limited by inability to detect low level NO production and insolubility of chelating agent. Use of fluorogenic probe DAF-FM is gaining more importance because of their simplicity, high sensitivity towards $\mathrm{NO}$ and are essentially independent of $\mathrm{pH}$ above $\mathrm{pH}$ 5.5. This probe is membranepermeant and deacylated by intracellular esterases to 4-amino-5-methylamino-2 $\mathrm{V}, 7 \mathrm{~V}$ difluorofluorescein. Presence of light leads to autoxidation of Diaminofluorescein-FM (DAF-FM) dye and simultaneous presence of $\mathrm{NO}$ and superoxide source (like xanthine + xanthine oxidase) decreases the fluorescence of Diaminofluorescein-FM (DAF-FM), resulting in underestimation of nitric oxide production (Balcerczyk et al., 2005). This limits the use of Diaminofluorescein-FM (DAF-FM) in stress-related study.

The activity of NOS can be measured by L-citrulline based assay (Tischner et al., 2007) and spectroscopic method (NADPH utilization method) (Gonzalez et al., 2012). Citrulline-based assay measures the formation of L-citrulline from L-arginine using ion exchange chromatography. The assay does not exactly quantify citrulline; any arginine derivative that does not bind to the cation exchange resin will give a signal and leads to false measurement and also involve radiolabelling which may be tedious to handle (Tischner et al., 2007). Spectrophotometric measurement of NOS activity has been widely regarded as a less expensive and sufficiently sensitive assay for routine laboratorial experiments.

Nitrate reductase activity can be measured by an in vitro or an easy to perform in vivo method (Nair and Abrol, 1973). We have used these protocols to study the effect of elevated $\mathrm{CO}_{2}(\mathrm{EC})$ and nitrate supply on nitrogen metabolism in wheat seedlings (Adavi and Sathee, 2019). S-nitrosylation of NR by EC induced NO produced in plants supplied with high nitrate concentration decreases the enzyme activity (Cheng et al., 2015; Du et al., 2016). 


\section{Materials and Reagents}

1. $50 \mathrm{ml}$ glass culture tubes without rim (Borosil, catalog number: 9820U08)

2. Scalpel Blade No.10 (Himedia, catalog number: LA76808)

3. Paint Brush (Faber-Castell, size-2)

4. Glass slide (Himedia, catalog number: LA76808) and cover slip (Himedia, catalog number: GW064)

5. Needle (Himedia)

6. Kimwipes ${ }^{\circledR}$

7. Moist filter paper

8. Butter paper bags

9. Wheat seed

10. Double distilled water

11. 2-(4-carboxy phenyl)-4,4,5,5-tetramethyl imidazoline-1-oxyl-3-oxide (cPTIO, Sigma-Aldrich, $200 \mu \mathrm{M}$, catalog number: C221)

12. Diaminofluorescein-FM (DAF-FM, Sigma-Aldrich, catalog number: D1821)

13. HEPES (Sigma-Aldrich, catalog number: RDD002)

14. Potassium nitrate $\left(\mathrm{KNO}_{3}\right)$ (Fischer Scientific, catalog number:13655)

15. N-nitro arginine methyl ester (L-NAME, Sigma-Aldrich, catalog number: N5751)

16. Phosphate buffer $200 \mathrm{mM} \mathrm{pH} 7.5$

17. Sodium nitroprusside (SNP, Sigma-Aldrich, catalog number: BP453)

18. Sodium tungstate (Na-Tungstate, Sigma-Aldrich, catalog number: 14304)

19. NEDD (Sisco Research Laboratories Pvt. Ltd, catalog number: 61166)

20. N-propanol

21. Ammonium Sulfonate (Sisco Research Laboratories Pvt. Ltd, catalog number: 62419)

22. $\mathrm{HgCl}_{2}$ (Sisco Research Laboratories Pvt. Ltd, catalog number: 25699)

23. Sulfanilamide (Sisco Research Laboratories Pvt. Ltd, catalog number:19689)

24. Ferric-EDTA (Sisco Research Laboratories Pvt. Ltd, catalog no 59389)

25. Assay buffer (Phosphate buffer, 100 mM, pH 7.0)

26. L-Arginine (Sisco Research Laboratories Pvt. Ltd, catalog number: 66637)

27. $\mathrm{MgCl}_{2}$ (Sisco Research Laboratories Pvt. Ltd, catalog number: 69396)

28. $\mathrm{CaCl}_{2}$ (Sisco Research Laboratories Pvt. Ltd, catalog number: 70650)

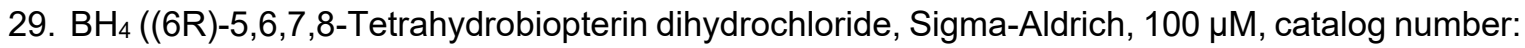
14304)

30. FAD (Sisco Research Laboratories Pvt. Ltd, catalog number: 87939)

31. FMN (Sisco Research Laboratories Pvt. Ltd, catalog number: 57443)

32. DTT (Sisco Research Laboratories Pvt. Ltd, catalog number: 84834)

33. PMSF (Sisco Research Laboratories Pvt. Ltd, catalog number: 87606)

34. NADPH (Sisco Research Laboratories Pvt. Ltd, catalog number: 77268) 
35. Bradford reagent (Genetix Biotech Asia Pvt. Ltd, catalog number: E530-1L)

36. $0.25 \% \mathrm{HgCl}_{2}$ in $0.1 \mathrm{~N} \mathrm{HCl}$

37. $7 \%$ sulfanilamide in $1 \mathrm{~N} \mathrm{HCl}$

38. $100 \mu \mathrm{M}$ Sodium nitroprusside (prepared in double distilled water)

39. $100 \mu \mathrm{M}$ Sodium tungstate) (prepared in double distilled water)

40. $0.1 \%$ NEDD (prepared in double distilled water)

41. $0.5 \%$ Ammonium sulfonate (prepared in double distilled water)

42. $0.2 \mathrm{mM} \mathrm{NADPH}$ (prepared in double distilled water)

43. Nitrogen free Hoagland solution (see Recipes)

44. NOS extraction buffer (see Recipes)

45. S-nitrosothiol extraction buffer (see Recipes)

46. HEPES-KOH with $\mathrm{pH} 7.5$ (see Recipes)

\section{Equipment}

1. Growth chamber (Conviron, Winnipeg, Canada, model: PGW 36,)

2. Watch glass (Himedia, catalog number: LA025)

3. Mortar and pestle

4. Fluorescence microscope (Zeiss AXIOSKOP 2)

5. UV-visible spectrophotometer (Analytik Jena, Germany, model: Specord Bio-200)

6. Refrigerated centrifuge (Sigma $3 K 30$ )

7. Aerator Pump

8. Water bath

\section{Software}

1. ImageJ (https://imagej.nih.gov/ii/download.html)

2. MS Excel

3. SPSS 10.0

\section{Procedure}

A. Plant growth

1. Pre-soak the wheat seeds in Petri plates lined with moist filter paper till they germinate for 5 days.

2. Transfer the uniforms seedlings to $50 \mathrm{ml}$ culture tubes containing nitrogen-free Hoagland solution (Recipe 1). Replenish the Hoagland solution every 3 days (Figure 1). The whole experiment was laid out at National Phytotron Facility, Indian Agricultural Research Institute (IARI), New Delhi in growth chambers (Model PGW 36, Conviron, Winnipeg, Canada). 
Growth condition:

Temperature: $25^{\circ} \mathrm{C} / 18^{\circ} \mathrm{C}$ (day/night)

Photoperiod: $14 \mathrm{~h} \mathrm{~N} / 10 \mathrm{~h} \mathrm{D}$

Photon flux density: $500 \mu \mathrm{mol} \mathrm{m} \mathrm{m}^{-2} \mathrm{~s}^{-1}$ (PAR)

Relative humidity (RH): $90 \%$

$\mathrm{CO}_{2}$ concentration: (i) $400 \pm 50 \mu \mathrm{l} / \mathrm{l}$ as ambient $\mathrm{CO}_{2}$ (AC)

(ii) $750 \pm 50 \mu \mathrm{l} / /$ as elevated $\mathrm{CO}_{2}(\mathrm{EC})$

B. Treatments

1. After 10 days of transfer, replenish the culture tubes with different set of treatments as mentioned in Table 1. Maintain 3 replication for each treatment.

2. Cover the mouth of test tubes with aluminum foil to avoid effect of volatile chemicals on neighbouring plants (Figure 1). Sodium nitroprusside (SNP), a source of NO; CPTIO, an effective NO scavenger-NAME an inhibitor of nitric oxide synthase, and Na-Tungstate, an inhibitor of NR can be used to understand the impact of No on regulation of NR activity. Detailed description on impact of EC on NO localization and NR activity in combination with SNP and inhibitors are discussed in Adavi and Sathee (2019).

Table 1. Treatment details

\begin{tabular}{|c|c|c|}
\hline Treatments & High N (5 mM) & Remarks \\
\hline 1 & Low $\mathrm{N}\left(0.05 \mathrm{mM} \mathrm{KNO}_{3}\right)$ & \\
\hline 2 & High $\mathrm{N}\left(5 \mathrm{mM} \mathrm{KNO}_{3}\right)$ & \\
\hline 3 & $\begin{array}{l}\text { Low } \mathrm{N}\left(0.05 \mathrm{mM} \mathrm{KNO}_{3}\right)+\mathrm{SNP} \\
(100 \mu \mathrm{M})\end{array}$ & Sodium nitroprusside (SNP) NO donor \\
\hline 4 & $\begin{array}{l}\mathrm{High} \mathrm{N}\left(5 \mathrm{mM} \mathrm{KNO}_{3}\right)+\mathrm{cPTIO} \\
(200 \mu \mathrm{M})\end{array}$ & $\begin{array}{l}\text { 2-(4-carboxy phenyl)-4,4,5,5-tetramethyl } \\
\text { imidazoline-1-oxyl-3-oxide (cPTIO) } \\
\text { scavenger of nitric oxide and reacts with } \\
\text { nitric oxide to form carboxy-PTI derivatives } \\
\text { which inhibits nitric oxide synthase. }\end{array}$ \\
\hline 5 & $\begin{array}{l}\operatorname{High} \mathrm{N}\left(5 \mathrm{mM} \mathrm{KNO}_{3}\right)+\mathrm{L}-\mathrm{NAME} \\
(400 \mu \mathrm{M})\end{array}$ & $\begin{array}{l}\text { N-nitro arginine methyl ester (L-NAME), } \\
\text { inhibitor of nitric oxide synthase. }\end{array}$ \\
\hline 6 & $\begin{array}{l}\text { High } \mathrm{N}(5 \mathrm{mM} \mathrm{KNO})_{3}+\mathrm{Na}- \\
\text { Tungstate }(100 \mu \mathrm{M})\end{array}$ & Na-Tungstate, inhibitor of nitrate reductase. \\
\hline
\end{tabular}




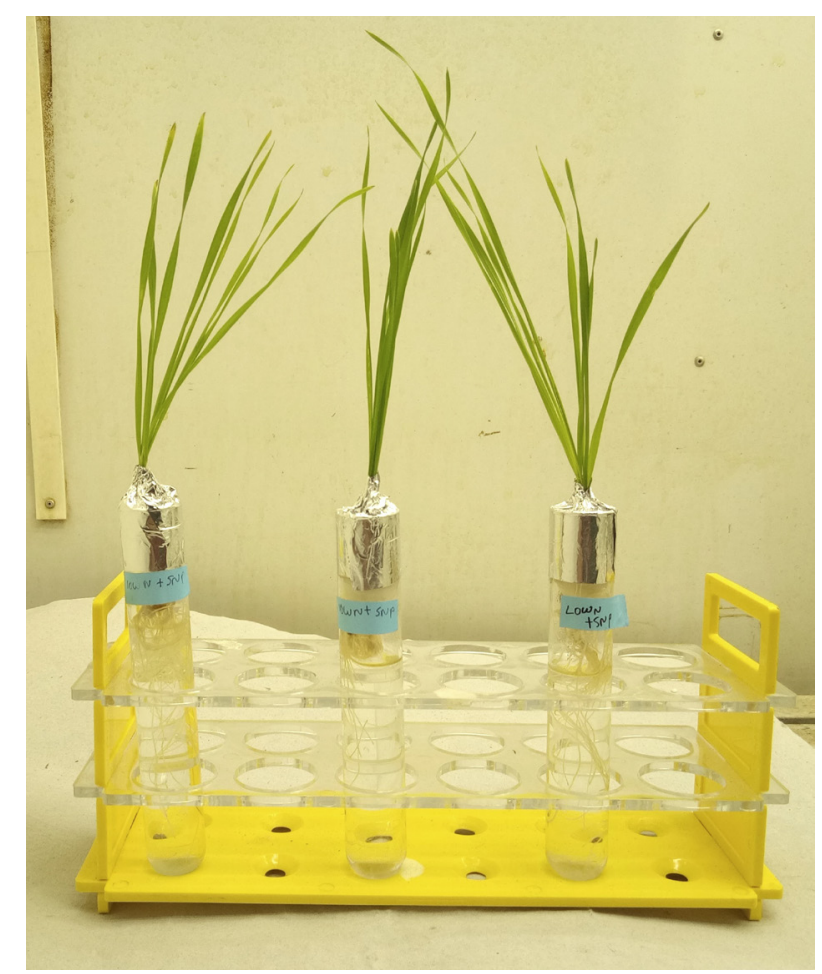

Figure 1. Representative image of plants grown in $\mathbf{5 0}$ ml culture tubes. Each treatment consisted of three tubes with 2 plants per tube.

C. Visualization of NO using fluorescent microscope

1. After $4 \mathrm{~h}$ of treatment, harvest the plants. Cut the root tips into small pieces measuring approximately $2 \mathrm{~mm}$ using surgical blade. Then immerse the root sections in the Diaminofluorescein-FM dye (5 $\mu \mathrm{M}$ DAF-FM in $20 \mathrm{mM} \mathrm{HEPES-KOH}$ with $\mathrm{pH} 7.5$ ) in a watch glass for $30 \mathrm{~min}$. After $30 \mathrm{~min}$, carefully take out the root sections and wash with HEPES-KOH buffer without dye 2-3 times till the excess dye is removed.

2. Transfer the root sections into glass slide carefully with help of paint brush and cover with cover glass. Drain out excess buffer with help of Kim Wipes.

3. Visualize the slides under a fluorescence microscope (Zeiss AXIOSKOP 2) at $495 \mathrm{~nm}$ excitation and $515 \mathrm{~nm}$ emission wavelengths and acquire the images (Figure 2).

4. Analyze the image and calculate the relative fluorescence with "Image J," a Java-based image processing program.

5. Set scale bar on the image using "Image J". 


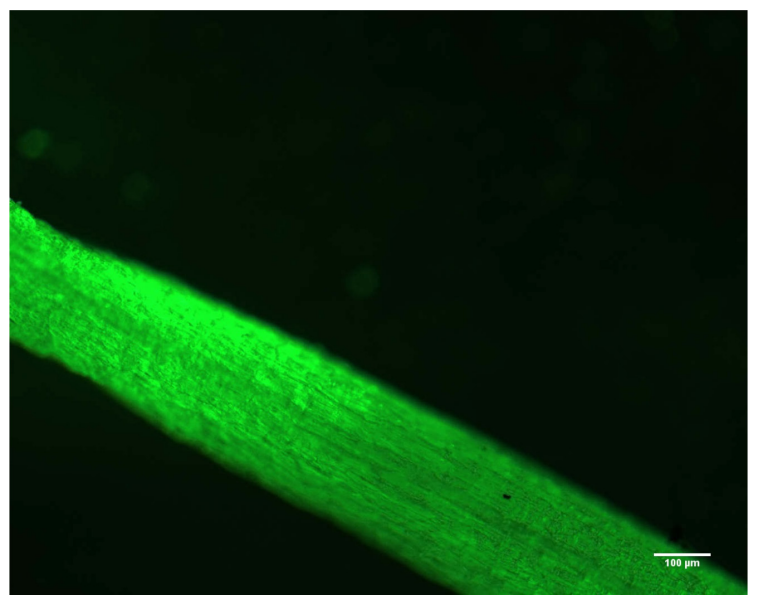

Figure 2. Representative image of nitric oxide visualized in wheat roots under fluorescent microscope

D. Estimation of Nitrate Reductase (NR) activity

1. Follow the same procedure for plant growth and treatments as mentioned (Procedures $A$ and B) above. Harvest the plants after $4 \mathrm{~h}$ of treatment.

2. Estimate in vivo nitrate reductase activity by estimating nitrite formed by the enzyme present in cells and nitrite formed is then diazotized using sulphanilamide in acidic medium and NEDD using the method described by Klepper et al. (1971) and modified by Nair and Abrol (1973). Estimate the nitrite amount using Evans and Nason method (1953).

3. Harvest the plants and store in labeled butter paper bags and keep on ice until weighing. Cut the samples (leaves and roots) into $2 \mathrm{~mm}$ pieces and mix thoroughly, weigh $0.3 \mathrm{~g}$ and add to ice cold incubation medium containing $3 \mathrm{ml}$ each of phosphate buffer $(0.2 \mathrm{M}, \mathrm{pH} 7.5)$ and potassium nitrate solution $(0.4 \mathrm{M})$. To this, add $0.2 \mathrm{ml}$ of $\mathrm{n}$-propanol.

4. Vacuum infiltrate the samples using a pump for $2 \mathrm{~min}(80-85 \mathrm{KPa})$ and then incubate in a water bath at $30^{\circ} \mathrm{C}$ for 30 min under dark conditions.

5. After incubation, place the tubes in a water bath $\left(70-80{ }^{\circ} \mathrm{C}\right)$ for $3-4$ min to stop the enzyme activity and for the complete leaching of nitrite into the medium.

6. Estimate the amount of nitrite produced by taking adequate amount of aliquot $(0.2 \mathrm{ml})$ in a test tube; to it add $1 \mathrm{ml}$ of sulphanilamide ( $1 \%$ in $1 \mathrm{~N} \mathrm{HCl}$ ). After mixing, add $1 \mathrm{ml} \mathrm{NEDD}(0.02 \%)$ and again mix well. Pink color is formed immediately, and after 20 min make the total volume up to $3 \mathrm{ml}$ with double distilled water.

7. Measure the absorbance using a UV-visible spectrophotometer (model Specord Bio-200) at 540 $\mathrm{nm}$.

8. Prepare the calibration curve using standard potassium nitrite solution.

9. Express the enzyme activity as $\mu \mathrm{mol}$ nitrite formed $\mathrm{g}^{-1} \mathrm{DW} \mathrm{h}^{-1}$. 
E. Estimation of Nitric oxide synthase (NOS) activity

1. Follow the same procedure for plant growth and treatments as mentioned (Procedures $A$ and B) above. Harvest the plants after $4 \mathrm{~h}$ of treatment.

2. Homogenize $0.5 \mathrm{~g}$ of tissue (leaf and root) samples in $5 \mathrm{ml}$ of cold extraction buffer in pre-chilled mortar and pestle. Centrifuge the homogenate at 10,000 $\mathrm{xg}$ for $15 \mathrm{~min}$ at $4{ }^{\circ} \mathrm{C}$ (Hageman and Hucklesby, 1971). Collect the supernatant to carry out enzyme assays. Determine the protein content of the supernatant by following Bradford' method (1976).

3. Determine the activity of NOS in the reaction mixture (Gonzalez et al., 2012) containing assay buffer (100 mM phosphate buffer pH 7.0), $1 \mathrm{mM} \mathrm{L-Arginine,} 2 \mathrm{mM} \mathrm{MgCl} 2,0.3 \mathrm{mM} \mathrm{CaCl} 2,4 \mu \mathrm{M}$ $\mathrm{BH}_{4}, 1 \mu \mathrm{M}$ FAD, $1 \mu \mathrm{M}$ FMN, $0.2 \mathrm{mM}$ DTT, $0.2 \mathrm{mM}$ NADPH with $100 \mu \mathrm{l}$ of tissue extract.

4. Observe the change in absorbance due to NADPH utilization at $340 \mathrm{~nm}$ for $1 \mathrm{~min}$. Reference was set using reaction mixtures containing distilled water instead of enzyme extract. Three replications of positive control with reaction mixture without L-Arginine was also maintained in each treatment. Use the extinction coefficient of NADPH $\left(\varepsilon=6.22 \mathrm{mM}^{-1} \mathrm{~cm}^{-1}\right)$ for calculating NOS activity.

\section{F. Estimation of S-nitrosothiols}

1. Formation of S-nitrosothiols is estimated from leaf and root tissues (Arc et al., 2013). All the steps need to be performed in dark condition. Follow the same procedure for plant growth and treatments as mentioned (Procedures $\mathrm{A}$ and $\mathrm{B}$ ) above.

2. Homogenize $0.5 \mathrm{~g}$ of tissue (leaf and root) samples in $5 \mathrm{ml}$ of cold s-nitrosothiols extraction buffer (Recipe 3) in pre-chilled mortar and pestle. Centrifuge the extract at 13,800 $\mathrm{g} g$ for $25 \mathrm{~min}$ at $4{ }^{\circ} \mathrm{C}$.

3. Mix the supernatant with $50 \mu \mathrm{l}$ ammonium sulfonate and incubate at room temperature for $2 \mathrm{~min}$. Then add $0.3 \mathrm{ml}$ each of sulfanilamide, $\mathrm{HgCl}_{2}$ and $\mathrm{NEDD}$ to the reaction mixture. Keep the reaction mixture under dark condition for $20 \mathrm{~min}$ at $30^{\circ} \mathrm{C}$.

4. Measure the absorbance using a UV-visible spectrophotometer (model Specord Bio-200) at 540 $\mathrm{nm}$.

\section{Data analysis}

MS Excel is used for calculations and also to plot the graphs. The least significant difference (LSD at $0.05 \%$ ) and mean separation using Duncan's multiple range test was computed by SPSS 10.0 . Plants exposed to EC conditions displayed higher accumulation of NO in NOS dependent manner and further details are described in Adavi and Sathee (2019). 


\section{$\underline{\text { Notes }}$}

1. Care should be taken to avoid exposure of DAF-FM dye to light, as the dye is light sensitive and may lead to auto-oxidation and false fluorescence.

2. Culture tube mouth should be properly covered with cotton and aluminium foil to avoid effect of volatile chemicals on neighbouring plants.

3. Care should be taken to avoid any damage to root sections while washing or transferring them to slides.

4. During measurement of NR, glasswares should be cleaned properly, rinsed with distilled water and air dried to avoid false color development.

\section{$\underline{\text { Recipes }}$}

1. Nitrogen free Hoagland Solution

$\begin{array}{lll}\text { Macronutrient } & \text { Molarity (M) } & \text { Quantity (ml/L of solution) } \\ \mathrm{K}_{2} \mathrm{SO}_{4} & 0.5 & 3.5 \\ \mathrm{MgSO}_{4} \cdot 7 \mathrm{H}_{2} \mathrm{O} & 1.0 & 2 \\ \mathrm{CaCl}_{2} & 1.0 & 2 \\ \mathrm{KH}_{2} \mathrm{PO}_{4} & 1 & 1 \\ \text { Micronutrient }_{3} & \text { Quantity (g/L of solution) } \\ \mathrm{H}_{3} \mathrm{BO}_{3} & 2.86 \\ \mathrm{MnCl}_{2} \cdot 4 \mathrm{H}_{2} \mathrm{O} & 1.81 \\ \mathrm{ZnSO} & \cdot 7 \mathrm{H}_{2} \mathrm{O} & 0.22 \\ \mathrm{CuSO}_{4} \cdot 5 \mathrm{H}_{2} \mathrm{O} & 0.08 & \\ \mathrm{Na}_{2} \mathrm{MoO}_{4} \cdot 2 \mathrm{H}_{2} \mathrm{O} & 0.02\end{array}$

Add micronutrient solution and $0.5 \%$ Ferric-EDTA solution (1 $\mathrm{ml}$ each) to one liter of solution of macronutrient and adjust the $\mathrm{pH}$ to 6.5 prior to use

2. NOS extraction buffer

Tris- $\mathrm{HCl}$ buffer, $50 \mathrm{mM} \mathrm{pH} 7.5$

$10 \mathrm{mM} \mathrm{MgCl}_{2}$

$1 \mathrm{mM}$ DTT

$1 \mathrm{mM}$ PMSF

3. S-nitrosothiol extraction buffer

25 mM HEPES-NaOH

$1 \mathrm{mM}$ EDTA, $\mathrm{pH} 7.8$

4. HEPES-KOH with $\mathrm{pH} 7.5$

$20 \mathrm{mM}$ HEPES was prepared in double distilled water and $\mathrm{pH}$ was adjusted to 7.5 with $\mathrm{KOH}$ 


\section{Acknowledgments}

This protocol was adapted from Adavi and Sathee (2019) and our other studies (unpublished). This study was supported by ICAR-Indian Agricultural Research Institute (institute projectCRSCIARISIL20144047279). SAB and BKP acknowledge ICAR- junior research fellowship support received during the course of the study.

\section{Competing interests}

The authors declare that there is no conflict of interest.

\section{References}

1. Adavi, S. B. and Sathee, L. (2019). Elevated $\mathrm{CO}_{2}$-induced production of nitric oxide differentially modulates nitrate assimilation and root growth of wheat seedlings in a nitrate dose-dependent manner. Protoplasma 256(1): 147-159.

2. Arc, E., Galland, M., Godin, B., Cueff, G. and Rajjou, L. (2013). Nitric oxide implication in the control of seed dormancy and germination. Front Plant Sci 4: 346.

3. Balcerczyk, A., Soszynski, M. and Bartosz, G. (2005). On the specificity of 4-amino-5methylamino-2', 7'-difluorofluorescein as a probe for nitric oxide. Free Radic Biol Med 39(3): 327335.

4. Bethke, P. C., Badger, M. R. and Jones, R. L. (2004). Apoplastic synthesis of nitric oxide by plant tissues. Plant Cell 16(2): 332-341.

5. Bogdan, C., Rollinghoff, M. and Diefenbach, A. (2000). The role of nitric oxide in innate immunity. Immunol Rev 173: 17-26.

6. Bradford, M. M. (1976). A rapid and sensitive method for the quantitation of microgram quantities of protein utilizing the principle of protein-dye binding. Anal Biochem 72(1-2): 248-254.

7. Cheng, T., Chen, J., Ef, A. A., Wang, P., Wang, G., Hu, X. and Shi, J. (2015). Quantitative proteomics analysis reveals that S-nitrosoglutathione reductase (GSNOR) and nitric oxide signaling enhance poplar defense against chilling stress. Planta 242(6): 1361-1390.

8. Conrath, U., Amoroso, G., Köhle, H. and Sültemeyer, D. F. (2004). Non-invasive online detection of nitric oxide from plants and some other organisms by mass spectrometry. The Plant $J 38(6)$ : 1015-1022.

9. Correa-Aragunde, N., Lombardo, C. and Lamattina, L. (2008). Nitric oxide: an active nitrogen molecule that modulates cellulose synthesis in tomato roots. New Phytol 179(2): 386-396.

10. de Pinto, M. C., Tommasi, F. and De Gara, L. (2002). Changes in the antioxidant systems as part of the signaling pathway responsible for the programmed cell death activated by nitric oxide and reactive oxygen species in tobacco Bright-Yellow 2 cells. Plant Physiol 130(2): 698-708.

11. Delledonne, M., Zeier, J., Marocco, A. and Lamb, C. (2001). Signal interactions between nitric 
oxide and reactive oxygen intermediates in the plant hypersensitive disease resistance response. Proc Natl Acad Sci U S A 98(23): 13454-13459.

12. Du, S., Zhang, R., Zhang, P., Liu, H., Yan, M., Chen, N., Xie, H. and Ke, S. (2016). Elevated $\mathrm{CO}_{2}$-induced production of nitric oxide (NO) by $\mathrm{NO}$ synthase differentially affects nitrate reductase activity in Arabidopsis plants under different nitrate supplies. J Exp Bot 67(3): 893904.

13. Evans, H. J. and Nason, A. (1953). Pyridine nucleotide-nitrate reductase from extracts of higher plants. Plant Physiol 28(2): 233-254.

14. Gonzalez, A., Cabrera Mde , L., Henriquez, M. J., Contreras, R. A., Morales, B. and Moenne, A. (2012) Cross talk among calcium, hydrogen peroxide, and nitric oxide and activation of gene expression involving calmodulins and calcium-dependent protein kinases in Ulva compressa exposed to copper excess. Plant Physiol 158(3):1451-1462.

15. Gupta, K. J., Fernie, A. R., Kaiser, W. M. and van Dongen, J. T. (2011). On the origins of nitric oxide. Trends Plant Sci 16(3): 160-168.

16. Hageman, R. H.and Hucklesby, D. P. (1971). Nitrate reductase from higher plants. In Methods in enzymology. Academic Press 23:491-503.

17. Hung, K. T., Chang, C. J. and Kao, C. H. (2002). Paraquat toxicity is reduced by nitric oxide in rice leaves. J Plant Physiol 159(2): 159-166.

18. Klepper, L., Flesher, D. and Hageman, R.H. (1971). Generation of reduced nicotinamide adenine dinucleotide for nitrate reduction in green leaves. Plant Physiol 48(5): 580-590.

19. Leshem, Y. Y. and Pinchasov, Y. (2000). Non-invasive photoacoustic spectroscopic determination of relative endogenous nitric oxide and ethylene content stoichiometry during the ripening of strawberries Fragaria anannasa (Duch.) and avocados Persea americana (Mill.). $J$ Exp Bot 51(349): 1471-1473.

20. Nair, T. V. R. and Abrol, Y. P. (1973). Nitrate reductase activity in developing wheat ears. Cell Mol Life Sci 29(12): 1480-1481.

21. Neill, S. J., Desikan, R. and Hancock, J. T. (2003). Nitric oxide signalling in plants. New Phytol, 159(1): 11-35.

22. Sun, A. (2018). The EPR method for detecting nitric oxide in plant senescence. In Plant Senescence. Humana Press pp: 119-124.

23. Tischner, R., Galli, M., Heimer, Y. M., Bielefeld, S., Okamoto, M., Mack, A. and Crawford, N. M. (2007). Interference with the citrulline-based nitric oxide synthase assay by argininosuccinate lyase activity in Arabidopsis extracts. FEBS J 274(16): 4238-4245.

24. Vanin, A. F., Svistunenko, D. A., Mikoyan, V. D., Serezhenkov, V. A., Fryer, M. J., Baker, N. R. and Cooper, C. E. (2004). Endogenous superoxide production and the nitrite/nitrate ratio control the concentration of bioavailable free nitric oxide in leaves. J Biol Chem 279(23): 24100-24107.

25. Xiong, J., Lu, H., Lu, K., Duan, Y., An, L. and Zhu, C. (2009). Cadmium decreases crown root number by decreasing endogenous nitric oxide, which is indispensable for crown root primordia initiation in rice seedlings. Planta 230(4): 599-610. 
26. Yaacov, Y. L., Wills, R. B. and Ku, V. V. V. (1998). Evidence for the function of the free radical gas nitric oxide (NO-) as an endogenous maturation and senescence regulating factor in higher plants. Plant Physiol Bioch.36(11): 825-833.

27. Yamasaki, H., Sakihama, Y. and Takahashi, S. (1999). An alternative pathway for nitric oxide production in plants: new features of an old enzyme. Trends Plant Sci 4(4): 128-129.

28. Yamasaki, H., Shimoji, H., Ohshiro, Y. and Sakihama, Y. (2001). Inhibitory effects of nitric oxide on oxidative phosphorylation in plant mitochondria. Nitric oxide, 5(3): 261-270.

29. Ye, Y. Q., Jin, C. W., Fan, S. K., Mao, Q. Q., Sun, C. L., Yu, Y. and Lin, X. Y. (2015). Elevation of NO production increases Fe immobilization in the Fe-deficiency roots apoplast by decreasing pectin methylation of cell wall. Sci Rep 5: 10746.

30. Yun, B. W., Skelly, M. J., Yin, M., Yu, M., Mun, B. G., Lee, S. U., Hussain, A., Spoel, S. H. and Loake, G. J. (2016). Nitric oxide and S-nitrosoglutathione function additively during plant immunity. New Phytol 211(2): 516-526.

31. Zhang, H., Shen, W. B. and Xu, L. L. (2003). Effects of nitric oxide on the germination of wheat seeds and its reactive oxygen species metabolisms under osmotic stress. Acta Bot Sin 45(8): 901-905. 